\title{
SAÚDE MENTAL E ECONOMIA SOLIDÁRIA: ANÁLISE DAS RELAÇÕES DE TRABALHO EM UMA COOPERATIVA DE CONFECÇÃO DE PORTO ALEGRE
}

\author{
Kátia Salete Barfknecht \\ Álvaro Roberto Crespo Merlo \\ Henrique Caetano Nardi \\ Universidade Federal do Rio Grande do Sul
}

\begin{abstract}
RESUMO: Este artigo aborda as vinculações entre o prazer, sofrimento e a organização do trabalho no cotidiano dos trabalhadores de uma cooperativa inserida no movimento da Economia Solidária. Como proposta do estudo, articulamos uma interpretação macro social do contexto socioeconômico, com uma análise micro social baseada na perspectiva da Psicodinâmica do Trabalho. Analisamos, em conjunto com os trabalhadores, as atividades de corte, costura e serigrafia desenvolvidas no empreendimento solidário. Os resultados apontaram para a identificação dos trabalhadores com o cooperativismo, bem como com a possibilidade das relações solidárias e do gerenciamento, transformando o sofrimento em prazer, favorecendo a saúde mental através da rediscussão constante da organização do trabalho e da criação de novos modos de viver o trabalho.
\end{abstract}

PALAVRAS-CHAVE: trabalho; saúde mental; economia solidária.

\section{MENTAL HEALTH AND SOLIDARITY ECONOMY: ANALYSIS OF LABOR RELATIONS IN A MANUFACTURE CO-OPERATIVE IN PORTO ALEGRE}

\begin{abstract}
This article focuses on the links of pleasure, distress, and work organization in the everyday life of workers of a cooperative associated with the social economy movement. Our research proposal seeks to articulate a macro-social interpretation of the socioeconomic context with a micro-social analysis based on the Work Psychodynamic theory. We have analyzed, with the workers, cutting, sewing, and silk-screen activities developed in the solidarity enterprise. The results have pointed out workers' identification with co-operativism, as well as with the possibility of the solidarity relations and management converting distress into pleasure, promoting the mental health through the continuous re-discussion of work organization and the creation of new ways of experiencing work.
\end{abstract}

KEYWORDS: work; mental health; solidarity economy.

Historicamente, as relações dos homens e das mulheres com o trabalho sofreram transformações relacionadas aos diversos modos de produção. O modo de produção capitalista sustenta uma lógica de competição, de individualismo e de busca do lucro, elementos esses que foram enfatizados e intensificados através da proposta de Taylor, a partir do desenvolvimento da Organização Científica do Trabalho (OCT), no início do século XX. Desde sua origem, a OCT buscou organizar o processo de trabalho, dividindo-o em concepção e execução, individualizando as tarefas e retirando do trabalhador o direito de conceber e criar. Segundo Dejours, Abdoucheli e Jayet (1994), Taylor tinha a intenção de instituir um modo operatório único, padronizando e generalizando todos os aspectos da organização do trabalho, anulando qualquer possibilidade de expressão e de desejo do trabalhador, limitando a satisfação à recompensa monetária. Hoje, a reestruturação produtiva introduziu novos modos operatórios mais flexíveis, mas, ao mesmo tempo, expulsou do mercado uma parcela da força de trabalho que não preenche os pré-requisitos exigidos aos trabalhadores para os postos de trabalho de boa qualidade.
No Brasil, convivem, atualmente, modalidades de organização e de gestão do processo produtivo com modelos de trabalho taylorizados, associados à reestruturação flexível. Tal junção pode ser chamada de modelo "Frankenstein" (Merlo, 2000), onde convivem as antigas agressões à saúde originadas nos precários e insalubres ambientes de trabalho, com as novas formas de sofrimento ligadas às exigências produzidas por ritmos desenfreados e pela redução drástica dos postos de trabalho. Esses modelos de organização do trabalho se associam à precariedade das trocas sociais, ao incremento do individualismo, à alienação e à flexibilização de relações trabalhistas, que, juntas, retiram as garantias e proteções historicamente conquistadas pelos trabalhadores assalariados. Essas transformações produzem efeitos sociais nefastos. O capitalismo globalizado em moldes neoliberais traz inúmeras consequiências, entre elas o aumento da miséria e da marginalização econômica e social.

Diante do desemprego crescente dos últimos anos, verificou-se que um significativo número de trabalhadores expulsos do mercado formal de trabalho passou a buscar uma reinserção através de experiências econô- 
micas de caráter solidário. Os saberes populares e solidários acumulados ao longo do tempo, no campo da produção e do trabalho, são suportes dessas experiências de formas associativas. Muitas dessas experiências buscaram constituir-se com base em concepções e relações de controle dos trabalhadores sobre o processo produtivo. Segundo Singer (1998), desde o século XIX, os trabalhadores vêm constituindo, por iniciativa própria, cooperativas e outras formas produtivas de tipo familiar, associativo e mesmo microempresarial. A partir da década de 1980, com o aumento do desemprego e da pobreza, vem aumentado o número de experiências de autogestão. Conforme o mesmo autor, no trabalho associativo, a efetivação dos princípios solidários só é possível através do exercício de novas formas de organização de trabalho e de relação com a produção. Além disso, esses empreendimentos dependem de instrumentos de fortalecimento do poder popular e da viabilidade econômica. Somente se atingidos estes objetivos, a economia solidária deixará de ser uma economia marginal e tornarse-á uma organização econômica, construindo novas formas de relações com a saúde e o trabalho que possibilitem uma organização do trabalho controlada pelos trabalhadores. Segundo pesquisa do Centro de Assessoria Multiprofissional - CAMP (2002), existe, hoje, uma parcela expressiva da população inserida no movimento de economia solidária, indicando o quanto este é um tema com possibilidades de mobilização e organização. Entretanto, estudos que enfoquem a saúde mental nos empreendimentos solidários ainda são raros. Assim, o propósito do presente artigo é buscar suprir uma lacuna da pesquisa neste novo campo de estudos sobre o trabalho.

Diante deste quadro, nos interessa estudar como as formas de organização do trabalho presentes na economia solidária se relacionam com a saúde mental dos trabalhadores, uma vez que as condições e a organização do trabalho atuam no funcionamento psíquico, desestabilizando ou favorecendo essa mesma saúde mental. A relação entre saúde mental e trabalho, segundo Dejours et al. (1994), referem-se, centralmente, à organização do trabalho, ou seja, à divisão das tarefas, ao seu conteúdo e à divisão dos trabalhadores no espaço de trabalho (funções, competências e relacionamentos). A divisão de tarefas promove o interesse e o sentido do trabalho através do modo operatório, enquanto a divisão de trabalhadores se refere às relações entre os sujeitos, aos investimentos afetivos, ao amor, ódio, amizade, solidariedade, confiança. Ainda segundo os autores acima, o sofrimento e o prazer são inerentes à história de enfrentamento dos trabalhadores com os riscos e pressões presentes no trabalho, agindo intensamente na dinâmica psíquica própria às relações de trabalho. $\mathrm{O}$ desafio é definir como os trabalhadores fazem seu trabalho, quais as ações suscetíveis de modificar o destino do sofrimento e como esse sofrimento pode ser transformado em criatividade e, assim, tornar-se um fator que favoreça a saúde.

Assim, ao investigarmos a relação saúde mental e o trabalho na economia solidária, tivemos como objetivo compreender se a organização do trabalho em um empreendimento identificado com os princípios solidários poderia, por basear-se na autogestão e na valorização da contribuição de cada trabalhador para o trabalho coletivo, favorecer a saúde mental desses mesmos trabalhadores. Ao explorarmos esta hipótese, tivemos sempre claro que, por estarem inseridos em relações de mercado hegemonicamente capitalistas, os empreendimentos solidários não estão livres da influência dos fatores geradores de prazer e sofrimento presentes nas formas de gestão características do capitalismo contemporâneo.

\section{Método}

A pesquisa buscou entender a dinâmica da organização do trabalho através da observação de campo e dos relatos dos trabalhadores a respeito dos aspectos que favorecem ou desfavorecem a saúde mental. Foram utilizadas duas estratégias metodológicas. Inicialmente, foram realizadas entrevistas semi-estruturadas para conhecer as trajetórias de vida e profissionais dos trabalhadores que compõem a cooperativa e, após, foi utilizada a Psicodinâmica do Trabalho (Dejours, 1988), buscando compreender a conformação do sofrimento psíquico a partir da percepção dos próprios trabalhadores. Estudouse as vinculações entre o sofrimento e a organização do trabalho à qual estão submetidos os trabalhadores, examinando também as dinâmicas de constituição de sistemas coletivos, as formas de exploração do sofrimento psíquico e as defesas coletivas. Refletiu-se sobre a organização do trabalho dentro da cooperativa e quais as suas repercussões na saúde mental dos trabalhadores, e evidenciou-se diversos aspectos a partir dos quais emergem as vivências de prazer e sofrimento.

O empreendimento escolhido foi a Cooperativa de Costureiras Unidas Venceremos (UNIVENS), localizada no bairro Sarandi, em Porto Alegre, RS. A escolha da UNIVENS ocorreu pelo fato da cooperativa estar no mercado de trabalho há nove anos e estar consolidada dentro do movimento de economia solidária, sendo sua trajetória reconhecida como exemplar pelos demais empreendimentos.

Como tinha-se como referência a estrutura e organização do trabalho taylorista, buscou-se observar como essa estrutura poderia "contaminar" essa outra forma de organizar o trabalho. Assim, as categorias analisadas foram: divisão do trabalho e divisão dos trabalhadores, relação entre os trabalhadores e o cotidiano do trabalho, tempo e ritmo de trabalho e sentidos e afetos relacionados ao fato de ser cooperativado na economia solidária. 


\section{Histórico da UNIVENS}

A cooperativa constituiu-se formalmente no ano de 1996, como iniciativa de propriedade e gestão coletiva. Desde 2002 é uma cooperativa associada à Cooperativa Central de Crédito e Economia Solidária - Central Única dos Trabalhadores (ECOSOL/CUT), que tem como objetivo central a cooperação, e não o lucro.

A cooperativa surgiu como alternativa de trabalho e renda em um momento de grande desemprego na região. As cooperativadas relataram que pensaram em criar um local para trabalhar, onde as decisões seriam tomadas em conjunto. Trinta e cinco mulheres reuniram-se em 1995, para criar uma cooperativa. Elas tinham entre 19 e 72 anos, muitas sabiam costurar, cuidavam dos filhos e precisavam gerar renda. Diziam, também, que precisavam de uma alternativa para dar sentido à vida. Elas estavam fora do mercado de trabalho por diferentes motivos: idade avançada, aposentadoria, doenças, filhos pequenos, escolaridade baixa e pouca qualificação. A partir da cooperativa, algumas trabalhadoras relataram que tiveram várias mudanças na vida, voltaram a estudar e passear: "Me sinto mais gente na sociedade".

A UNIVENS é uma referência de cooperativa que consegue gerar trabalho e renda, dentro do movimento da economia solidária de Porto Alegre. O grupo, neste seu percurso, recebeu apoio técnico e financeiro de diversas instituições (SMIC/PMPA, ECOSOL, CÁRITAS, etc.). A cooperativa, atualmente, é constituída por 22 trabalhadores, sendo nove sócias fundadoras, que continuam na cooperativa. Em janeiro de 2005, encerrou-se um processo de incubação de nove anos promovido pela Secretaria da Indústria e Comércio de Porto Alegre e a cooperativa transferiu-se para um prédio próprio.

Os sócios da cooperativa participam ativamente dos fóruns de economia solidária, orçamento participativo, eventos de economia solidária (encontros, seminários, feiras, cursos), produzem tanto por encomenda, como trabalham em lojas e feiras, vendendo as camisetas produzidas pela cooperativa.

\section{Os sujeitos da pesquisa}

Nove trabalhadores foram entrevistados: duas costureiras que trabalhavam dentro do espaço da cooperativa, duas costureiras que trabalhavam no próprio domicílio, uma cooperativada que realiza a atividade de corte e recepção do cliente e quatro integrantes da serigrafia. Nesta escolha, buscou-se abarcar todos os setores e atividades da cooperativa.

O grupo que participou da pesquisa foi constituído de sete mulheres e dois homens com idades entre 22 e 59 anos. Destes, a maioria tinham filhos pequenos, eram casados e necessitavam da renda para o sustento da casa. A escolaridade média restringia-se ao ensino fundamental e com pouca qualificação profissional formal. Outras habilidades e competências foram aprendidas na cooperativa com as trocas de experiências.

Além das entrevistas, realizou-se observação das atividades e permaneceu-se no campo de maio a novembro de 2005. Os resultados das análises foram discutidos com os integrantes da cooperativa, buscando, desta maneira, refletir sobre as nossas conclusões em conjunto com os trabalhadores, buscando, assim, além de partilhar o conhecimento produzido, adicionar maior consistência à análise. Cabe ressaltar, ainda, que todos os participantes assinaram Termo de Consentimento Livre e Esclarecido.

\section{Resultados}

Na análise da relação entre a organização do trabalho e a saúde mental dos trabalhadores da UNIVENS, conforme perspectiva deles mesmos, apontaram-se alguns aspectos centrais já mencionados anteriormente, ou seja: a divisão do trabalho e a divisão dos trabalhadores; relações entre os trabalhadores e o cotidiano do trabalho; o tempo e o ritmo de trabalho e os sentidos e afetos relacionados ao fato de ser cooperativado na economia solidária. Partiuse desses itens, para interpretar os resultados.

O tempo de participação desses trabalhadores na UNIVENS era variável, desde integrantes que estavam no projeto de formação da cooperativa há nove anos, até os que estavam somente há três meses. Todos tiveram experiências anteriores no mercado de trabalho. Nos relatos referiram sobre o percurso, a organização, a atividade que exerceram e que sentimentos tinham em relação ao trabalho na cooperativa.

\section{A divisão do trabalho e a divisão dos trabalhadores}

Na cooperativa, os sócios dividem-se nas atividades de corte, costura e serigrafia. A produção de uma camiseta, por exemplo, é um produto que passa por todos esses setores.

O setor do corte é composto por quatro sócias, três delas são fundadoras da cooperativa. A atividade de corte antecede à costura, nela se recebem os tecidos e se faz o corte das peças, conforme a encomenda do cliente. Esta atividade é dividida em várias etapas, que são realizadas por todas as integrantes do setor. A renda da produção é partilhada de maneira igual entre as sócias do grupo. As cooperativadas recepcionam os clientes e encaminham as peças cortadas para as costureiras e a serigrafia, e, após, entregam o produto acabado aos clientes. Este setor centraliza as atividades da cooperativa e tem um significado primordial para a costura. Segundo as cooperativadas, esta atividade "é a base da costura".

$\mathrm{Na}$ atividade de costura são realizados diversos produtos de confecção: camisetas, moletons com a marca da cooperativa, camisetas, guarda-pós, aventais, moletons e abrigos para clientes facção. ${ }^{1}$ Além destas peças, são cri- 
adas roupas com retalhos coloridos para uso próprio. A atividade de costura recebe do corte as peças e, algumas vezes, da serigrafia. O grupo da costura é constituído por doze trabalhadoras, sendo que quatro trabalham no espaço da cooperativa e oito em suas casas.

No início, os cooperativados não tinham espaço coletivo, então criou-se a possibilidade de trabalhar individualmente em casa. Atualmente, algumas costureiras alegam diferentes motivos para trabalhar em casa, apesar da cooperativa, no momento da pesquisa, ocupar três salas da Incubadora da Zona Norte. O espaço e o horário de trabalho se confundem com as atividades domésticas, gerando diversas dificuldades em relação ao espaço e à organização do trabalho:

Costuro e tenho compromissos com a minha casa e meus filhos, vou até tarde da noite costurando, não tenho hora para nada. Faço todo o trabalho de casa e tenho o compromisso de entregar a costura em dia.

Percebe-se que as costureiras que trabalham em casa não têm horário definido e a costura toma conta da vida. Algumas costureiras, além de irem diariamente à cooperativa, recebem costura em casa. As costureiras "de fora" buscam e trazem a produção em sacolas. As colegas levam mais trabalho para elas, se necessário, após o final do expediente.

Algumas conseguem impor limites às demandas de produção, outras não. No conjunto dos setores são as costureiras que sofrem mais pressões, talvez porque não sejam organizadas (no mesmo espaço). Observa-se que o trabalho toma conta dos horários de lazer, como se não houvesse mais nada para fazer, além de trabalhar.

Todas as quatro costureiras trabalhavam com produção individualizada, e utilizam uma caderneta para marcar a produção e ganham pelo que produzem. A organização individual entre as costureiras impede uma comunicação efetiva entre as trabalhadoras em relação ao gerenciamento da organização coletiva do trabalho. $\mathrm{O}$ que prevalece é a visão individualista, dentro de um sistema cooperativado. A existência de um espaço compartilhado com as demais colegas de trabalho promove um conviver coletivo, a experimentação de formas de produzir, as trocas de saberes, enfim as trocas sociais, que são de muita importância para os trabalhadores.

A atividade de serigrafia iniciou há seis anos, e os integrantes atuais ingressaram posteriormente. O setor da serigrafia é constituído por quatro cooperativados que trabalham coletivamente. Todos fizeram curso preparatório ao entrar e após, "os integrantes foram passando o ensinamento, um para o outro". Os sócios relataram que aprenderam solidariamente todas as etapas, mas as dividem porque cada integrante tem uma preferência específica por determinada atividade. A renda da produção é divi-dida de maneira igual para os cooperativados do grupo, mesmo para quem tenha faltado ao trabalho por motivo justificado.

\section{Relações entre os trabalhadores \\ e o cotidiano do trabalho}

A UNIVENS foi criada por um grupo de mulheres que se conheciam, algumas tinham uma relação muito próxima de amizade, outras se aproximaram através de amigas. Assim, definiu-se uma relação de solidariedade, de parceria, que tinha como pano de fundo as relações afetivas e um conhecimento profissional específico:

As colegas são minhas amigas pessoais. Fizemos passeios e festa juntos. Todo mundo participa da vida do outro, como família, alguns bem próximos, outros não, mas todo mundo se dando.

Muitas relações de amizade surgiram na cooperativa e outras já existiam. Todos os 22 cooperativados residem nas proximidades e/ou no mesmo bairro. Atualmente, grande parte dos trabalhadores tem laços de parentesco: " $E$ praticamente a minha família, minha irmã, prima”.

$\mathrm{O}$ aprendizado e as trocas sociais e afetivas fazem parte dessas relações cotidianas na cooperativa. Segundo Dejours (1999), trabalhar não é apenas exercer atividades produtivas, mas conviver com os colegas de trabalho para chegar a uma composição, aprender, opinar, dar parecer e deliberar coletivamente.

Essa solidariedade na aprendizagem e gestão coletiva é evidente no relato dos cooperativados sobre como aprenderam a especificidade técnica e como adquiriram novos modos de trabalhar ouvindo as colegas e/ou organizando um jeito próprio de exercer a atividade com a experiência: "Adoro costurar, faço o que gosto e me sinto livre. Muitas atividades de costura aprendi com as colegas de trabalho".

$\mathrm{O}$ discurso da solidariedade e das trocas de saberes está presente também no relato das costureiras:

Eu consegui ouvir a H., que tem experiência, aprendi com ela. Antes a minha costura na manga não ficava bonita. Esse jeito que aprendi com a H. deixa a manga bonita e facilita a costura. Eu já tentei passar para as outras, mas nem todas se propõem a aprender com as colegas.

Além das falas que remetem às trocas coletivas, também aparecem as tensões entre os setores, devido à necessidade de manter um ritmo de produção no cotidiano de trabalho:

Em relação ao trabalho da costura e da serigrafia, às vezes temos dificuldades de acertar o tempo para produção de um ou de outro. Isso é uma relação no trabalho do dia-a-dia.

O envolvimento da equipe de coordenação com os distintos setores, através de um misto de afeto, responsa- 
bilidade e controle, exerce um papel importante na cooperativa e no movimento de economia solidária. Esses fatores permitem que a cooperativa se mantenha em movimento e busque a construção de uma solidariedade ampliada, para além do empreendimento em si. Entretanto, a relação da coordenação com os integrantes não é tranqüila. Na fala dos trabalhadores, são expressas críticas sobre a necessidade de valorização igualitária de todos os entrevistados, a dificuldade de compreender o envolvimento da coordenadora no movimento estadual e nacional de economia solidária e, ao mesmo tempo, reconhecer o seu papel na inserção bem-sucedida da UNIVENS no mercado: "Todo grupo grande precisa de líder, a nossa tem garra, batalha, todos sabem que ela é líder, não devemos trocar. Mas outras devem ser valorizadas".

Percebe-se que o conflito de idéias é mal visto e, portanto, pouco explicitado. Os trabalhadores têm receio do confronto. Sentem o conflito como um rompimento e não como uma possibilidade de transformar ou criar novos conceitos. Percebem e relatam as dificuldades, mas não conseguem se organizar para levar os assuntos para a discussão nas assembléias: "Confronto existe quando não se concorda, surgem atritos. Então tu tem que ter muita calma e paciência para falar cada assunto".

"Precisamos discutir sem medo de falar, pois se continuar um só falando, muita gente vai sair daqui. Tem que mudar". Esta tensão não explicitada leva a momentos de competição na cooperativa. Essa competição é abafada pelos trabalhadores sob o manto da solidariedade e como forma de evitar conflitos e discussões construídas pelo grupo.

\section{O tempo e o ritmo de trabalho}

Na cooperativa, o tempo e o ritmo de trabalho são flexíveis, os trabalhadores, na maioria das vezes, conseguem impor tempo e ritmo próprios na produção. No grupo, somente as costureiras organizam individualmente o horário de trabalho. Nos setores de corte e de serigrafia, a combinação dos horários é coletiva.

Conforme a percepção dos cooperativados, o tempo e o ritmo de trabalho aumentam quando há mais encomendas, com menor prazo para a entrega e/ou se um dos setores tem problemas e atrasa:

O trabalho é calmo, o ritmo aumenta se chega trabalho que é para ser entregue muito rápido. Isso acontece, às vezes, tem pouco trabalho, e se não tem, saímos mais cedo, todos, ou um ou outro.

No setor de corte e de serigrafia, existe liberdade para organizar o horário de trabalho, contar com os colegas quando é necessário, afastar-se por breves períodos ou não ir trabalhar por diferentes motivos. Esta combinação de horários acontece em todos os setores desde a formação da cooperativa. O trabalhador tem sua necessidade reconhecida pelos colegas e estes realizam o seu trabalho de forma solidária. Todos os entrevistados afirmaram a importância desta conquista proporcionada pela gestão solidária:

Na cooperativa dá para fazer o horário que quiser, pode-se marcar compromissos durante o horário de trabalho, mas é importante avisar que não virá, é a responsabilidade e a solidariedade juntas.

Os cooperativados sentem a diferença de tempo e ritmo em relação aos seus trabalhos anteriores. Eles já vivenciaram experiências de pressão intensa relacionada ao horário fixo, tempo exíguo, ritmo acelerado da produção e à dificuldade de realizar pausas (ir ao banheiro, fumar).

O tempo e o ritmo em que cada setor deve desenvolver suas atividades e encaminhar a sua produção para outro setor eram partes muito importantes do trabalho na cooperativa. E, se no interior de cada setor a relação é tranqüila, não podemos dizer o mesmo da relação entre os setores. Escutamos muitas queixas referentes à organização da dinâmica entre os setores, principalmente com relação aos atrasos da produção, que fazem com que o próximo grupo tenha que estabelecer um tempo e um ritmo algumas vezes excessivo para entregar uma produção no prazo combinado com o cliente.

A produção das atividades na cooperativa é uma decisão coletiva; a presidente socializa a demanda da produção com os grupos separadamente ou na assembléia mensal. Os trabalhadores aceitam a produção, mas queixam-se de que, inúmeras vezes, sentem pressão no trabalho referente ao tempo e ritmo, o que gera sofrimento.

\section{Sentidos e afetos relacionados ao fato de ser cooperativado na economia solidária: prazer e sofrimento}

Apesar dos entrevistados considerarem que a cooperativa estava consolidada, um contexto social de dúvidas, incertezas e questionamentos marcava ainda a vida desses trabalhadores. Guiados por necessidades imediatas de trabalho e renda, eles romperam com a miséria econômica e viveram o desafio de exercer atividades dentro de um empreendimento solidário. A maioria dos cooperativados "carregavam" e "acreditavam" no discurso solidário e eram reconhecidos e respeitados pelos grupos do movimento de economia solidária. Esse reconhecimento dos integrantes do movimento e do público que compra os bens produzidos na economia solidária, nos vários eventos nacionais e internacionais, tem um efeito positivo em relação à sua identificação como "trabalhadores solidários", reforçando o investimento subjetivo e produzindo uma valorização referente ao trabalho e à posição que ocupam na sociedade. 
Dejours et al. (1994) afirmam que o sofrimento é inevitável na história do sujeito. $O$ desafio é definir quais são as ações suscetíveis de modificar o destino do sofrimento, ou seja, como o sofrimento é transformado em criatividade e como pode, desta forma, trazer benefícios à identidade do trabalhador, em relação ao seu fazer. Com esta perspectiva, entendeu-se o sofrimento não como uma debilidade orgânica, proveniente de uma doença ou de condições péssimas de trabalho, mas como sofrimento diante da insatisfação originada por uma organização rígida e imutável. A questão colocou-se no "sentido" ou na "significação" do sofrimento e da doença, dependendo de como o sujeito estava engajado nas relações que estabelecia com seu trabalho e com o social.

Para os trabalhadores da economia solidária, a organização do trabalho proposta possibilitava o exercício das funções de trabalhador e de gestor do empreendimento no cotidiano da cooperativa. Mas, significava também poder entrar e permanecer em um mercado de consumo envolvido pelo sistema social hegemônico marcado pelos valores do capitalismo.

Neste contexto, o sofrimento se expressava nas pressões do trabalho coletivo, nas exigências de produção, nos modos de viver o trabalho e, principalmente, no desafio de construir a autogestão na cooperativa. O sofrimento vivido por esses trabalhadores se manifestava nas dificuldades de comunicação, nas trocas e debates do trabalho coletivo, em relação à sensação de incapacidade para gerenciar o empreendimento, na ausência das garantias trabalhistas associadas ao mercado formal (carteira assinada, salário, férias, fundo de garantia, etc.) e nas dúvidas sobre a saúde e o futuro. Na cooperativa, estavam presentes o estresse, as dores no corpo, a culpa e as incapacidades consideradas como aspectos "normais" para quem trabalha.

As estratégias defensivas necessárias à proteção da saúde mental têm o objetivo de proteger o sujeito contra as pressões provenientes do trabalho, mas, conforme Dejours (1999), também contribuem para estabilizar a relação desse sujeito com o trabalho, dificultando qualquer possibilidade de mudanças, funcionando como uma armadilha que insensibiliza quanto ao que o faz sofrer. Torna aceitável para o trabalhador aquilo que não deveria ser. Em alguns momentos, as estratégias defensivas se tornam tão importantes para os trabalhadores que, quando esforçam-se para enfrentar as pressões do trabalho, acabam transformando as estratégias de defesa em objetivos para si.

Neste contexto, percebeu-se as lutas entre fatores patogênicos da organização do trabalho e as condutas defensivas elaboradas pelos próprios trabalhadores na cooperativa, as quais se relacionavam com a forma como os trabalhadores viviam as relações que estabeleciam com seu trabalho, como reconstruiram as lógicas das pressões que os faziam sofrer e como constituiam as estra- tégias defensivas. Desta forma, as lutas desses trabalhadores podem ser entendidas como expressões de esperança e desejo em relação à UNIVENS. Os trabalhadores encontraram significados criativos. Conforme Dejours (1994), este poder de ação, de grande fecundidade, na visão da produtividade, da segurança, da qualidade e da transformação da organização do trabalho, testemunha justamente aquilo que seriam os ganhos da emancipação diretamente investidos no trabalho e nas relações sociais.

\section{Discussão}

$\mathrm{Na}$ sociedade capitalista e, mais especificamente, no Brasil, o fato de ser trabalhador de um empreendimento autogestionável, é andar por outra via, é participar de "outra economia", uma economia marginal e vulnerável do ponto de vista dos valores dominantes, assim como do ponto de vista da inserção no mercado. A proposta do movimento de economia solidária tem como objetivo reverter e superar a economia capitalista individualista e competitiva, na qual o capital e o mercado determinam a conduta e a vida dos trabalhadores. Trata-se de tentar construir um exercício de poder compartilhado, de relações sociais e de cooperação entre os trabalhadores, privilegiando o trabalho em detrimento do capital; enfim, vivenciar outra forma de organização do trabalho e de sociedade.

Na cooperativa, a organização do trabalho é um desafio a ser enfrentado todos os dias. Alguns trabalhadores percebem e constroem a experiência de um espaço de aprendizado, trocas sociais, novas formas de relação com o trabalho e com a produção. Outros vêem a cooperativa como um espaço passageiro, única e imediata alternativa para gerar renda, sem comprometimento com a autogestão.

Os princípios da economia solidária, solidariedade, trabalho coletivo e autogestão, estão presentes nos relatos de todos os cooperativados, porém, alguns identificamse totalmente com estes princípios e outros parcialmente, pois remetem para a coordenação a responsabilidade de dar conta da efetivação destes valores guias no empreendimento. A centralização do setor do corte, composto por três sócias fundadoras da UNIVENS e integrantes da coordenação, reflete um gerenciamento que parece ser necessário para a cooperativa e para os sócios. O envolvimento da coordenação é considerado afetivo, de liderança, de autoridade e também centralizador. Essa centralização do poder, em princípio, se opõe à proposta de autogestão da economia solidária. Segundo Albuquerque (2003), o exercício do poder compartilhado propicia a autonomia do coletivo de trabalhadores e qualifica as relações sociais de cooperação. Os trabalhadores da cooperativa, entretanto, afirmam que a 
centralização do trabalho é positiva, importante, pois facilita o trabalho, mas também percebem seu lado negativo em relação à centralização do poder e à necessidade de socializar as competências para a gestão. Éalgo dúbio, que explicita uma dificuldade central do trabalho na gestão solidária, cuja tendência é de delegar o gerenciamento ao outro.

Para ser cooperativado na economia solidária é necessário um investimento subjetivo importante para aprender a relacionar-se no coletivo. Embora se perceba que na UNIVENS o trabalho não é sempre coletivo (no sentido de executado em um mesmo espaço e decidido em conjunto), uma vez que a serigrafia e o corte têm atividades compartilhadas e a costura é individual, percebemos que a cooperativa caminha na direção da afirmação da gestão coletiva. Entretanto, esta só se efetiva mediante o investimento pessoal de cada membro. Um investimento desse tipo, para Dejours (1999), quando não é percebido, causa sofrimento patogênico, o que é ameaça à saúde mental. Quando o trabalho é compartilhado e reconhecido pelos colegas, o sentido do sofrimento transforma-se em prazer no trabalho (o sofrimento criativo).

A organização do trabalho em relação ao espaço é um aspecto de análise, pois os setores de corte, de serigrafia e seis costureiras trabalhavam no espaço da cooperativa, e oito costureiras usavam as suas casas como espaço de trabalho. As costureiras possuiam uma organização de trabalho individual, mesmo sendo cooperativadas. Segundo Schmidt e Perius (2003), entre os princípios cooperativos não existe consideração negativa em relação à proposta do trabalho em espaços fora da cooperativa, porém as decisões devem ser coletivas, democráticas. $\mathrm{Na}$ proposta da economia solidária, as trocas durante o trabalho e o trabalho coletivo são considerados primordiais para promover as relações de solidariedade. Entretanto, no caso em análise, vislumbrou-se que na relação de trabalho e renda existem duas realidades na cooperativa. As falas das costureiras as aproximam de uma visão individualista inserida em um sistema cooperativo.

Outra perspectiva é percebida nas falas dos trabalhadores dos setores de corte e de serigrafia, onde estes assumem a produção, dividem a renda, organizam o tempo e ritmo de trabalho coletivamente. Eles reconhecem as diferenças da organização de trabalho que se estabelece na cooperativa em relação à experiência com a organização dos trabalhos anteriores, com os horários rígidos, hierarquia fixa e produção por metas diárias, etc. O trabalho na cooperativa é diferente de uma empresa capitalista em relação aos horários e às decisões. A flexibilidade discutida com os colegas no corte e na serigrafia demonstra uma outra relação de trabalho que promove o "coleguismo" e a solidariedade. Os trabalhadores constroem outros modos de trabalhar, outros acessos a espaços sociais e outros vínculos importantes, como a ampliação do tempo dedicado à vida doméstica.
Na cooperativa, os trabalhadores falam da importância das relações familiares e comunitárias. Este aspecto é reforçado pelo fato de que integrantes de muitas famílias trabalham na UNIVENS e residem no bairro. Os relatos explicitam a centralidade das trocas afetivas e da solidariedade. Identificamos que existem as relações de trabalho associadas com às relações familiares, nas quais é difícil separar a geração de renda (negócios) das trocas afetivas. As relações próximas e familiares nos empreendimentos de economia solidária podem trazer à tona a dimensão da economia da dádiva, expressão da solidariedade que promove a criação e reconstrução de laços sociais. A solidariedade é o laço social que une trabalhadores em torno de um ideal. Entretanto, também pode-se apontar que as relações de afeto e a dificuldade de separar família e trabalho podem se constituir em um fator de limitação do debate e da explicitação do conflito.

A dificuldade de ser cooperativado e viver o trabalho na economia solidária aparece de diferentes maneiras, principalmente quando os sentimentos em relação aos cuidados com a saúde confrontam-se com as demandas cotidianas de produção e da busca do lucro, necessário para manter os investimentos na cooperativa, as quais são atravessadas pelo individualismo, pela competição, pela pressão e pelo estresse da produção. As costureiras são as mais vulneráveis, pois trabalham por peça produzida: se não trabalham, não ganham. Os trabalhadores sentiam a necessidade de ajudar as colegas quando essas adoeciam, mas nas assembléias ainda não chegavam a nenhuma solução que pudesse auxiliar o trabalhador doente. Relatavam que auxiliavam financeiramente as colegas que adoeciam por solidariedade, mas não de forma organizada, de acordo com princípios estabelecidos internamente no regramento da cooperativa.

A impossibilidade de trabalhar devido à doença ou dor apareceu pouco nos relatos dos integrantes da cooperativa que participaram da pesquisa e, algumas vezes, foram banalizadas como algo que é "natural" da profissão. Percebeu-se que, mesmo na cooperativa, onde eles podiam estabelecer o tempo e ritmo de trabalho, o desgaste se fazia presente na vida dos trabalhadores. A naturalização dos riscos ergonômicos parecia se constituir em uma estratégia defensiva, uma vez que estes não eram discutidos pelo grupo. É como se o fato de o trabalho ser auto ou coletivamente gerido protegesse o trabalhador do risco de adoecer. A cooperativa apresentava uma forma de organização do trabalho que mesclava princípios da economia solidária e elementos da organização de trabalho do capitalismo. E este é o modelo da economia solidária que tem se afirmado, uma vez que os trabalhadores têm aceitado novos desafios.

A UNIVENS é uma cooperativa da economia solidária que está sujeita às pressões do mercado. Percebeu-se conflitos e questionamentos relativos ao empreendimento enquanto parte do campo da economia solidária. Os con- 
flitos surgiram quanto à relação do mercado solidário com o mercado capitalista. Os pressupostos do sistema cooperativista enaltecem o coletivo, e o capitalismo promove o individualismo. Assim, ser autônomo e pagar a Previdência Social, dentro de um empreendimento solidário, parecia ser a única alternativa encontrada em relação ao mercado de trabalho capitalista no que se refere a uma forma de proteção social mais duradoura e estável.

Para finalizar, pode-se afirmar que, apesar das tensões encontradas, a pesquisa evidenciou que a maioria dos trabalhadores se identificava com o cooperativismo, estabelecendo uma prática de reflexão sobre o cotidiano do trabalho, a solidariedade e o gerenciamento da cooperativa. Percebeu-se, na discussão com os trabalhadores, que a busca permanente de capacitação e de assessoria para a instituição era primordial para constituir e desenvolver a gestão solidária, para a autogestão acontecer de fato na cooperativa.

\section{Notas}

1. Facção é a palavra utilizada na cooperativa para designar peças cortadas, de roupas de marcas (etiquetas da moda), que chegam somente para costura.

2. Como são chamadas as costureiras que trabalham em casa e buscam diariamente as peças para costura na cooperativa.

\section{Referências}

Albuquerque, P.P. (2003). Autogestão. Em A.D. Cattani (Ed.), A outra economia (pp.37-45). Porto Alegre: Vozes; UFRGS.

CAMP - Centro de Assessoria Multiprofissional (2002). Pesquisa Economia Popular Solidária. Pesquisa/Ação Economia Popular e Solidária. Porto Alegre: CAMP.

Dejours, C. (1988). A loucura do trabalho-estudo em psicopatologia do trabalho ( $3^{\mathrm{a}}$ ed.). São Paulo: Cortez/Oboré.

Dejours, C. (1999). A banalização da injustiça social. Rio de Janeiro: Fundação Getúlio Vargas.

Dejours, C.; Abdoucheli, E \& Jayet, C. (1994). Itinerário teórico em Psicopatologia do trabalho. São Paulo: Atlas.
Merlo, A.R.C. (2000). Transformações no mundo do trabalho e a saúde. Em A. Jerusalinky, A.C. Merlo \& A.L. Giongo et al. (Eds.), O valor simbólico do trabalho: e o sujeito contemporâneo (pp. 271-278). Porto Alegre: Artes e Ofícios.

Singer, P. (1998). Uma utopia militante: repensando o socialismo. Petrópolis, RJ: Vozes.

Schmidt, D. \& Perius, V. (2003). Cooperativismo e cooperativa. Em A.D. Cattani (Ed.), A outra economia (pp.63-71). Porto Alegre: Vozes; UFRGS.

Kátia Salete Barfknecht é mestre em Psicologia Social e Institucional pela Universidade Federal do

Rio Grande do Sul. katiab@cpovo.net

Álvaro R.C. Merlo é doutor e docente do Programa de Pós-Graduação em Psicologia Social e Institucional da Universidade Federal do Rio Grande do Sul. Rua Ramiro Barcelos, 2600/sala 401- CEP 90035-003 PortoAlegre, RS merlo@ufrgs.br

Henrique C. Nardi é doutor e docente do Programa de Pós-Graduação em Psicologia Social e Institucional da Universidade Federal do Rio Grande do Sul. hcnardi@terra.com.br

Saúde mental e economia solidária: análise das relações de trabalho em uma cooperativa de confecção de Porto Alegre

Kátia Salete Barfknecht, Álvaro Roberto Crespo Merlo \& Henrique Caetano Nardi

Recebido: 20/11/2005

$1{ }^{\text {a }}$ Revisão: $15 / 06 / 2006$

Aceite final: 07/07/2006 